\title{
El diálogo interreligioso impulsado por el Consejo Episcopal Latinoamericano (CELAM)
}

\author{
PATRICIO MERINO BEAS* \\ Universidad Católica de la Santísima Concepción (Chile) \\ CEBITEPAL (CELAM) \\ pmerino@ucsc.cl
}

\begin{abstract}
Resumen
Este escrito es fruto de una investigación documental y bibliográfica realizada en el Archivo General del Consejo Episcopal Latinoamericano (AG-CELAM). Busca presentar una síntesis del impulso que ha realizado el CELAM en orden al diálogo interreligioso. Este no ha sido un camino fácil y aún hay mucho por hacer. No obstante, en el ámbito de la Iglesia Católica, el CELAM ha sido un permanente animador de las orientaciones de los obispos en esta temática, plasmadas en el Concilio Vaticano II y las Conferencias Generales del Episcopado Latinoamericano.
\end{abstract}

Palabras clave: Diálogo interreligiosos, CELAM, comunión, colegialidad, bien común.

\section{Interreligious dialogue supported by the Latin American Bishops Council}

\begin{abstract}
This paper is the product of documentary and bibliographic research in the General Archives of the Latin American Bishops' Council (CELAM) and it endeavors to provide a synthesis of the efforts that CELAM has made in regard to interreligious dialogue. This has not been an easy path to follow and there is still much more yet to be done. However, in the context of the Catholic Church, CELAM has been a persistent dynamic force, encouraging bishops on this topic, according to the guidelines found in the documents of $V$ atican II and the General Conferences of Latin American Bishops.
\end{abstract}

Key words: Interfaith dialogue; CELAM, communion, and collegiality; common good.

Doctor en Teología, Universidad Pontificia de Salamanca. Profesor de teología sistemática en el Instituto de Teología de la Universidad Católica de la Santísima Concepción - Chile y profesor invitado en la Facultad de Teología de la Universidad Santo Tomás de Colombia. Director de la Escuela Teológica y Vicerrector Académico del CEBITEPAL-CELAM.

Esta investigación forma parte del proyecto interno del CELAM que tiene por objetivo indagar en los aportes de la institución a la pastoral latinoamericana y caribeña en sus sesenta años de historia. 
El Consejo Episcopal Latinoamericano (CELAM) es una de las instituciones colegiadas más importantes de la Iglesia católica, desde sus estructuras se apoyan las tareas evangelizadoras y pastorales de los episcopados nacionales. El año 2016 el CELAM cumplió sesenta años (se fundó en 1956) y en ese marco de celebración se ejecutaron varios proyectos de investigación tendientes a mostrar los aportes de esta institución a las distintas áreas de la evangelización y la pastoral. Uno de ellos es la animación del diálogo interreligioso. En este sentido, este artículo es uno de los frutos de ese proyecto, buscando ofrecer al lector e investigadores una visión panorámica del diálogo interreligioso animado por el CELAM en América Latina y El Caribe.

La investigación fue sobre todo documental, tanto en los archivos del CELAM, como en las publicaciones de los planes globales y los informes de gestión de los diversos cuatrienios administrativos. Con este escrito buscamos mostrar al gran público esta área de la animación pastoral del CELAM, que suele ser una de las más desconocidas. Procurando abrir el apetito para que otros investigadores puedan continuar con investigaciones más precisas.

He dividido este texto en cinco puntos. El primero presenta una panorámica histórica del proceso que siguió la asunción del diálogo interreligioso en el CELAM desde sus inicios y hasta hoy. Destacando las ideas teológico pastorales y algunos nombres importantes. El segundo punto presenta en forma sintética el tratamiento que el diálogo religioso o interreligioso tuvo en las cinco Conferencias Generales del Episcopado Latinoamericano. El tercer punto se centra en las relaciones del CELAM con diversas instituciones que representan al pueblo judío. El cuarto capítulo ofrece algunas líneas de desarrollo que presenta la teología india (y afroamericana).

Para muchos es desconocido que ella ha nacido como impulso del CELAM en diálogo con los pueblos originarios, buscando reconocer y destacar su aporte cultural y religioso al proceso de evangelización y la configuración de la piedad popular actual. Este punto presenta igualmente algunos hilos teológicos prometedores para la configuración de un diálogo interreligioso desde un aporte latinoamericano. Finalmente, en el punto cinco, ofrezco un elenco bibliográfico de las publicaciones del CELAM en la temática que nos atañe, con el fin de que puedan servir de insumo a otros investigadores interesados. 
1. DE LA DEFENSA DE LA FE AL ENCUENTRO-DIÁLOGO CON LA DIVERSIDAD CULTURAL Y RELIGIOSA. SINOPSIS HISTÓRICA

El diálogo interreligioso al interior del CELAM hunde sus raíces en la preocupación por la defensa de la fe y la cambiante situación socio-religiosa del continente latinoamericano. La perspectiva de la defensa de la fe fue la actitud que primó en los primeros años del CELAM y se mantuvo hasta el Concilio Vaticano II (2000). Luego de las directrices del Concilio, sobre todo teniendo en cuenta las Constituciones Lumen Gentium y Gaudium et Spes, y las Declaraciones Nostra Aetate y Dignitatis Humanae, la perspectiva eclesiológica se renovó y esto permitió abrir nuevas posibilidades de desarrollo teológico y pastoral. Años después y en la medida que el análisis de lo religioso se relacionó con el de la cultura, éste se enriqueció aún más, pudiendo incorporar nuevos sujetos y rostros, como la teología india y la afroamericana, reconociendo que en América Latina había una diversidad religiosa (Merino, 2010, 2012).

Quizá por la idea de que en América Latina predominaba una homogeneidad cristiana y católica, el tema del diálogo interreligioso tuvo en sus inicios un acento reducido al diálogo con los judíos y no creyentes. Este proceso se notó a su vez en la estructura misma del CELAM. Por ejemplo, en la XI Asamblea Ordinaria del CELAM celebrada en Lima en 1967 se pensó en la idea de constituir un secretariado especial que tuviera tres secciones, a saber: Ecumenismo, no creyentes y no cristianos. Esta fórmula no prosperó, puesto que se creó el Departamento de Ecumenismo, pero años más tarde nació la sección para no creyentes. Esta sección para los no creyentes fue proyectada en 1972, en la XIV asamblea ordinaria celebrada en Sucre (Bolivia), pero fue creada en 1973. Su primer secretario ejecutivo fue el P. Jaime Vélez (Colombia), el Obispo responsable fue el Secretario General del CELAM, Alfonzo López Trujillo. Entre sus tareas estuvo crear conciencia del problema de la no creencia, investigar el ateísmo, la secularización, el indiferentismo, la magia, el espiritismo, el ocultismo, etc. Esta sección fue pionera en estudiar y dar cuenta de la importancia de la religiosidad popular, frente a la secularización. Finalmente, quisiera destacar que la sección para los no creyentes organizó un importante encuentro de profesores de teología y filosofía, para abordar la cuestión de Dios en el contexto Latinoamericano. Este se realizó en Lima en 1974. Fruto del encuentro se publicó el libro: CELAM (1974). Dios. Problemática de la no - creencia en América Latina. Posteriormente, en la medida que el gran tema englobante fue la cultura, los temas de esta sección pasaron a integrarse a una nueva sección, esta área del CELAM hoy se llama Departamento de Cultura y Educación. 
Los obispos latinoamericanos estaban acostumbrados a los movimientos acatólicos, la masonería, la hechicería, la brujería, etc. (Río de Janeiro, 1955). Pero los datos que iban arrojando los estudios socio-religiosos visibilizaron nuevos actores: grupos protestantes provenientes de iglesias no históricas; iglesias libres y nuevos movimientos religiosos (Medellín, 1968). Todavía hubo que esperar algunos años, para que los rostros de los otros religiosos, incluidos los pueblos originarios, tuvieran una visibilidad mayor.

En el caso propiamente del diálogo interreligioso este se reducía a la relación con los judíos. Prácticamente hubo que esperar al intervalo de tiempo que va desde la III Conferencia General del Episcopado en Puebla (1979) hasta la IV Conferencia General del Episcopado en Santo Domingo (1992), cuando el tema de la cultura y la inculturación aparecieron con fuerza, para que los rostros de religiones originarias comenzaran a ser visibles en los documentos del magisterio latinoamericano (Merino, 2012). Recién en 1985 en la asamblea ordinaria del CELAM celebrada en San José de Costa Rica se solicitó que la sección de Ecumenismo se enriqueciera con el diálogo religioso, pasando a llamarse Sección de Ecumenismo y Diálogo Religioso (CELAM, 1987).

Propiamente tal, la visibilización del diálogo interreligioso tomó impulso con la IV Conferencia de General del Episcopado en Santo Domingo (1992), aunque las bases estuvieron en Puebla (1979), donde el tema de la cultura y la inculturación pasaron a tener un lugar destacado en la reflexión y acción pastoral. Aquí tuvo mucha influencia la reflexión teológica de Lucio Gera, entre otros, y las categorías de análisis que realizaba la denominada teología del pueblo desde Argentina (Scannone, 2017).

En la preocupación por la creciente secularización y, sobre todo, de la indiferencia religiosa que presentaba América Latina, los obispos latinoamericanos dijeron:

(Hay un) ...despertar del sentido y necesidad de lo religioso, motivado, entre otras razones, por la crisis de las ideologías. Al mismo, tiempo se observa un aumento del indiferentismo religioso, especialmente en los sectores urbanos (CELAM, 1991: 31).

Durante el cuatrienio 1995-1999 habría que destacar que en el plan global del CELAM aparece la indicación específica de promover espacios de diálogo, no sólo con los judíos, sino también con los musulmanes (CELAM, 1995). No obstante, en otro informe del año 1999, la sección reconoce la falta de actividades de relación con la comunidad musulmana (CELAM, 1999). 
La Declaración Dominus Iesus (2000) marcó muchas de las actividades del cuatrienio 1999-2003. Se organizaron dos reuniones regionales (países Bolivarianos y del Cono Sur) con alcance ecuménico e interreligioso (CELAM, 1999). También fueron muy importantes las distintas iniciativas de encuentro y oración que se desarrollaron con motivo del Jubileo. Destacó la Asamblea Interreligiosa celebrada en Roma en 1999. Por otra parte, entre las dificultades se acusa la falta de animación en lo referente al diálogo interreligioso y se dice que la principal razón es la complejidad del tema. Hay que agregar que persistía el problema de que muchas diócesis no tenían comité para el diálogo ecuménico e interreligioso. Y en muchas Conferencias Episcopales no había un secretario ejecutivo dedicado al tema (CELAM, 1999).

Durante el cuatrienio 2003-2007 la sección de Ecumenismo y Diálogo Interreligioso se incorporó al Departamento de Comunión Eclesial y Diálogo. Lo más destacable y diferenciador respecto a otros períodos fue el acercamiento a otros organismos y movimientos de diálogo interreligioso, tales como: Iniciativa de Religiones Unidas y Movimiento de Religiones por la Paz (CELAM, 2003: 78).

La V Conferencia General del Episcopado Latinoamericano y de El Caribe realizada en Aparecida (2007) y sus conclusiones marcarán el rumbo de los siguientes cuatrienios. El correspondiente a 2007-2011 tiene entre sus logros el haber retomado los encuentros latinoamericanos entre católicos y judíos (México, 9-10 de septiembre de 2008), después de catorce años de no haberse realizado. El encuentro tuvo como tema: La vivencia de la fe y la familia en el contexto del mundo actual.

El cuatrienio 2011-2015 tuvo dos importantes encuentros dedicados a estudiar la relación entre Iglesia - Estado (Quito, 2012) y la libertad religiosa (Buenos Aires, 2014). También destacó el encuentro realizado con los líderes religiosos de América Latina y el Caribe convocado por el Foro Cristiano Mundial (Quito, 2014). También, un representante del CELAM participó en el Congreso Internacional Judío, organizado por la International Council of Christians and Jews (ICCJ) y la Confraternidad Argentina Judeo Cristiana (CELAM, 2011).

Para el cuatrienio 2015-2019, el Plan Global del CELAM contempla:

(Mantener) Relaciones eclesiales con instituciones cristianas y diálogo interreligioso. Específicamente en el Paso 5.15 se dice: "Cultivar en comunión con el Pontificio Consejo para el diálogo Interreligioso, y en colaboración con los Departamentos de Comunión Eclesial y Diálogo y Cultura y Educación, diálogo con las religiones no cristianas presentes en la región, especialmente con los judíos, musulmanes y religiones indígenas y de origen africano (CELAM, 2015: 85). 
A su vez, en el programa número 10 del Departamento de Comunión Eclesial y Diálogo, se tiene como objetivo específico:

Fomentar en y con las Conferencias Episcopales el espíritu ecuménico desde una Iglesia en camino hacia la plenitud de la comunión, y promover el Diálogo Interreligioso desde una Iglesia en salida, mediante la oración, el encuentro fraterno, el testimonio común, el compromiso de vida y el cuidado de la tierra para contribuir a la convivencia fraterna y a la paz (CELAM, 2015: 88).

\section{El DiÁlogo INTERRELIGIOSO EN LAS CONFERENCIAS GENERALES} DEL EPISCOPADO LATINOAMERICANO

A nivel del magisterio de la Iglesia Católica es sabido que el Concilio Vaticano II ha sido crucial en el impulso y discernimiento del diálogo interreligioso. El magisterio de los Papas Pablo VI, Juan Pablo II, Benedicto XVI y Francisco han impulsado de manera diferenciada, pero constante el diálogo interreligioso. También han sido importantes algunos documentos, tales como: Documento Diálogo y Anuncio (1991) y la Declaración Dominus Iesus (2000). Por otra parte, los documentos conclusivos de las Conferencias Generales del Episcopado Latinoamericano reunidas después del Concilio, Medellín, Puebla, Santo Domingo y Aparecida, han incorporado de manera creciente una palabra pastoral sobre los pueblos originarios, la cultura, la misión evangelizadora, la religiosidad popular y el diálogo interreligioso, pero no ha sido su cometido el elaborar una reflexión teológica sistemática sobre estas cuestiones.

En el apartado anterior, ya hemos dicho una palabra desde la I Conferencia General realizado en Río de Janeiro (1955) y la II realizada en Medellín (1968). A partir de la III Conferencia General del Episcopado (Puebla, 1979: 1103-1104. 1110- 1111. 1116- 1118. 1123) se ha incorporado en el magisterio y en la práctica pastoral oficial el tema del diálogo interreligioso, lo que ha ido de la mano con el reconocimiento tácito de un pluralismo cultural y religioso en el continente. La influencia en la Conferencia de Puebla de la Evangelii Nuntiandi de Pablo VI fue determinante, de ahí que el mismo título de la tercera Conferencia fuera: La evangelización en el presente y el futuro de América Latina.

La IV Conferencia General celebrada en Santo Domingo (1992), en el contexto de los quinientos años del Evangelio en el continente, acogió el tema del diálogo interreligioso y el reconocimiento de la diversidad cultural y religiosa (Santo Domingo, 1992: 136-138), de hecho, sabemos que el tema de la cultura, la inculturación y la nueva evangelización fueron una 
de sus preocupaciones fundamentales. En Santo Domingo se insistió mucho en la necesidad de hacer una distinción entre las religiones no cristianas, que vienen de fuera del continente y que van teniendo una creciente presencia, y las originarias:

Buscar ocasiones de diálogo con las religiones afroamericanas y de los pueblos indígenas, atentos a descubrir en ellas las semillas del Verbo, con un verdadero discernimiento cristiano, ofreciéndoles el anuncio integral del Evangelio y evitando cualquier forma de sincretismo religioso (Santo Domingo, 1992: 138).

En la V Conferencia General del Episcopado Latinoamericano y El Caribe celebrada en Aparecida (2007) hay un desarrollo más detallado y preciso (Aparecida, 2007: 43-59. 74-82. 227-239), allí se hace alusión directa al "nuevo pluralismo religioso" (Aparecida, 2007: 100g). Destaca que es necesario ser conscientes de la transformación religiosa que está teniendo el continente debido a la globalización y la creciente inmigración, como asimismo, debido a los grandes cambios culturales (y religiosos) que afectan a la transmisión de la fe (Aparecida, 2007: 100d). Por lo tanto, el creciente pluralismo religioso del continente, como también, el desarrollo de la eclesiología de comunión, hacen cada vez más necesario y posible el diálogo interreligioso (Merino, 2010 y 2012). La eclesiología de comunión que presenta Aparecida es entonces clave para el futuro desarrollo de la pastoral interreligiosa y también para el ecumenismo (Merino, 2009).

Para Aparecida el anuncio del Evangelio y el diálogo, constituyen una forma de acoger la gracia de Dios, y le da suma importancia al testimonio (común) y al compromiso (Aparecida, 2007: 238). El diálogo, lejos de hacer perder la identidad cristiana, la supone. Aparecida llama a: "invertir en el conocimiento de las religiones" (Aparecida, 2007: 238) y a valorar el aporte del diálogo interreligioso para la educación para la paz y la búsqueda del bien común:

El diálogo interreligioso, además de su carácter teológico, tiene un especial significado en la construcción de la nueva humanidad: abre caminos inéditos de testimonio cristiano, promueve la libertad y dignidad de los pueblos, estimula la colaboración por el bien común, supera la violencia motivada por actitudes religiosas fundamentalistas, educa a la paz y a la convivencia ciudadana: es un campo de bienaventuranzas que son asumidas por la Doctrina Social de la Iglesia (Aparecida, 2007: 239).

Aparecida da mucha relevancia al diálogo con los judíos (2007: 235) y las religiones monoteístas (2007: 237). Finalmente, en la misma línea que 
lo hizo Santo Domingo, Aparecida hace una especial mención a los pueblos originarios (2007: 125. 530), sobre todo, por la sabiduría con que enriquecieron la fe cristiana. Los obispos en Aparecida llaman a defender la dignidad de los pueblos originarios y la inculturación de la fe.

Más recientemente, hay que destacar que junto con las conclusiones de Aparecida está siendo de mucha importancia y marcando el camino del CELAM y su Plan Global (2015-2019), la Exhortación Evangelii Gaudium y la propuesta del Papa Francisco de una Iglesia en salida (Francisco, 2013: 250-251. 255-258).

\section{El diÁlogo con el Pueblo Judío en América latina}

El Departamento de Ecumenismo comenzó en el año 1967 con un secretario adjunto dedicado a las relaciones con el judaísmo, a cargo del P. Luis Rivas (Argentina). Su sede estaba en Buenos Aires.

El diálogo interreligioso, propiamente tal, era diálogo con los judíos. La asamblea del Departamento de Ecumenismo del CELAM que se realizó en 1970, hizo suyas las conclusiones y recomendaciones de la reunión judeo - católica de Bogotá, que había sido convocada por el CELAM y la Asociación B 'nai B 'rith del 20 al 21 de agosto de 1968 (CELAM, 1980).

En 1972 se iniciaron encuentros anuales del grupo mixto de trabajo entre la sección de Ecumenismo y el Congreso Judío Latinoamericano. El primero se realizó en la ciudad de Lima. Estos encuentros se prolongaron regularmente. Fruto de estos encuentros y estrechas relaciones, hubo varias publicaciones que presentamos en el punto cinco de este escrito. Las mutuas relaciones no se limitaron a estos encuentros, sino que se nutrieron de constantes visitas mutuas entre las autoridades del CELAM y los Rabinos de los distintos países. Como, asimismo, algunos programas de cooperación interreligiosa comunes (CELAM, 1980).

Finalmente, tienen también un lugar muy destacado en las mutuas relaciones la oración en conjunto, sobre todo para pedir la paz. Todos los cuatrienios han mantenido acciones concretas de diálogo interreligioso con los judíos y con organizaciones judías. Cabe destacar, sobre todo, la relación mantenida por más de cuarenta años entre el CELAM y el Congreso Judío Latinoamericano, que tiene su sede en Buenos Aires. Dentro de las más importantes actividades previstas en conjunto es un encuentro para celebrar juntos los cincuenta años de la Declaración Conciliar Nostra Aetate, que como sabemos marcó un antes y un después en la relación entre católicos y judíos (CELAM, 2011). 


\section{LA TEOLOGÍA INDIA Y AFROAMERICANA: LOS ELEMENTOS TEOLÓGI- COS QUE ANIMAN EL DIÁLOGO INTERRELIGIOSO}

Esta estrecha relación que ha habido entre el diálogo interreligioso, la configuración religiosa latinoamericana y la cultura, nos llevan a integrar en este escrito el impulso que el CELAM le ha dado a la Teología India y poco a poco a la Afroamericana. Durante el cuatrienio 1991-1995 se propuso: "mantener un diálogo serio con la así llamada Teología India y la Teología Negra” (CELAM, 1991: 184). No obstante, hay que hacer notar que en la estructura del CELAM este tema no pertenece al Departamento de Comunión Eclesial y Diálogo, donde está actualmente radicada la temática del Diálogo Interreligioso, sino que se encuentra dentro del Departamento de Cultura y Educación, justamente, por la estrecha relación que este tema tiene con la cultura latinoamericana (originaria).

El CELAM está acompañando e impulsando decididamente la teología india, porque ve en ella un sincero deseo por establecer un diálogo entre los pueblos originarios, incluida sus tradiciones religiosas ancestrales, y el Evangelio. Algo similar ocurre con la teología y pastoral afroamericana (Nkafu, 2013).

Los avances realizados con esta experiencia de la teología india están abriendo perspectivas para todo el diálogo interreligioso en perspectiva latinoamericana. Nos preguntamos: ¿Qué elementos teológicos encontramos en esta teología india latinoamericana que puedan iluminar un diálogo interreligioso en perspectiva latinoamericana?

Luego de analizar los distintos artículos de las actas de los encuentros de estudio que se han realizado, estamos en condiciones de distinguir, al menos, dos acentuaciones importantes e íntimamente relacionadas que se pueden ofrecer como semilla para un diálogo interreligioso de tinta latinoamericano.

\subsection{El énfasis histórico de la salvación}

El primero de ellos y punto de partida es la afirmación de una salvación (y revelación) realizada por Dios en la historia, a partir aquí, se comprende que el designio salvífico de Dios revelado en el acontecimiento de Jesucristo y del Espíritu, es trinitario y pascual, tanto por su contenido, como por su dinamismo. Este dinamismo es actualizado en la historia por la acción del Espíritu Santo que permanentemente estaría remitiendo al acontecimiento pascual.

La comprensión de la salvación realizada en la historia implica tomar en serio también las mediaciones culturales de esa salvación, es decir, la 
historia misma y la cultura de los pueblos. De este modo, se está en condiciones de afirmar la posibilidad de encontrar en las expresiones de las religiones indígenas y afrodescendientes, signos de diversas dimensiones de la salvación pascual mediatizadas por la acción del Espíritu Santo que también obra en ellos. En la metodología que siguen los teólogos que intentan realizar el diálogo entre el Evangelio, la religiosidad indígena y la afroamericana, queda de manifiesto que si se miran en el Evangelio las imágenes concretas de cómo se entiende allí la salvación, es posible encontrar elementos convergentes con las experiencias de las religiones indígenas. Así, por ejemplo, se deja ver una comprensión de la salvación como solución a un problema, como absolución de la culpa del pecado, como sanación, como perdón, como reconciliación, como protección, etc.

Lo mismo ocurriría si se entiende la salvación como aspiración a la liberación integral y la vida buena. En este caso habría otras similitudes: paso del odio al amor, de la mentira a la verdad, del orgullo a la humildad, del rencor al perdón, etc. Otro tanto ocurriría si vemos la salvación como promesa de una nueva relación con Dios, que expresa ante todo una experiencia relacional vivificadora: salvación como comunión o armonía con Dios, con los demás hombres y con la naturaleza; salvación como iluminación y conciencia de verdad; salvación vivida como agradecimiento, como hospitalidad, como obediencia a la voluntad de Dios, etc.

Ellas actúan como elementos que permiten una apertura propia de estos pueblos al acontecimiento cristiano, que de hecho ha permitido a muchos de los indígenas, afrodescendientes y sus pueblos aceptar el evangelio como respuesta plena a sus búsquedas ancestrales, como una preparación hecha por Dios mismo. Estas similitudes o convergencias, se entienden, obviamente, a nivel de contenido y no de formas de expresarse.

Dentro de este mismo punto, el de la salvación realizada en la historia, se ubicaría el importante tema de las semillas del Verbo. Cabe advertir aquí, que el uso de la categoría semillas del Verbo, es toma en sentido amplio y común, como presencia e impronta atemática en la propia religión ancestral del Verbo eterno del Padre, por medio del cual y para quien fueron creadas todas las cosas.

Justamente, basándose en esta categoría y en su actualización por el Espíritu, así como también en la necesaria purificación de ellas mediante el acontecimiento histórico de la encarnación y del misterio pascual, habría que leer la simbología, las ritualidades y mitologías de las religiones originarias y afrodescendientes. Sabemos que esta categoría teológica es muy importante y tiene una gran relevancia para el tema del diálogo interreligioso. Su raíz se remonta a los Padres de la Iglesia y se ha retomado con fuerza desde el Concilio Vaticano II (2000) (Nostra Aetate 2 y Gaudium et Spes 22). 
Bajo estas perspectivas, está siendo revisada por los actores teológicos presentes en el ejercicio de la teología india y afroamericana. La acogida de esta categoría en Latinoamérica tiene importantes antecedentes. Así, por ejemplo, Medellín (1968, en el apartado dedicado a la pastoral popular y las conclusiones n. 6,5); Puebla (1979, n. 401-403); Santo Domingo, 1992, n. 138, 245) y Aparecida (2007), donde en el número 4 se dice:

Las semillas del Verbo presentes en las culturas autóctonas, facilitaron a nuestros hermanos indígenas encontrar en el Evangelio respuestas vitales a sus aspiraciones más hondas: Cristo era el Salvador que anhelaban silenciosamente.

Y en el n. 529 agrega:

Como discípulos de Jesucristo, encarnado en la vida de todos los pueblos descubrimos y reconocemos desde la fe las semillas del Verbo presentes en las tradiciones y culturas de los pueblos indígenas de América Latina. De ellos valoramos su profundo aprecio comunitario por la vida, presente en toda la creación, en la existencia cotidiana y en la milenaria experiencia religiosa, que dinamiza sus culturas, la que llega a su plenitud en la revelación del verdadero rostro de Dios por Jesucristo.

El uso teológico de esta categoría siempre se encuentra en relación con la plenitud de la revelación y la fe, manifestada en los acontecimientos de la encarnación del Verbo y de la efusión del Espíritu. No es utilizada reduccionistamente, como podríamos ver en una visión que separe el Cristo cósmico de la persona de Jesús. A su vez, se plantea la necesidad de un constante discernimiento. En este punto, se propone considerar y mantener tres principios:

a. La centralidad del anuncio explícito del kerigma bíblico, sin el cual se renunciaría a la identidad cristiana.

b. La buena nueva que se presenta como continuidad: es decir, como acogida del Dios que ya ha estado cerca y presente en el pueblo, mediante su historia y tradiciones culturales y religiosas.

c. La buena nueva como novedad: es decir, como un acontecimiento plenificador, que da cumplimiento a las esperanzas originadas en la historia y la tradición religiosa y cultural milenaria, como expresión del Dios siempre mayor y trascendente. 
4.2. Las perspectivas de la teología de la creación

El segundo elemento teológico y, a la vez, antropológico se encuentra en la teología de la creación. En este sentido, el lema del cuarto simposio de teología india puede resumir muy bien la idea central: El sueño de Dios en la creación humana y en el cosmos.

La teología de la creación sirve como punto de encuentro para el diálogo con los pueblos y su religión originaria. Desde él se parte, para luego ir accediendo, tanto a la búsqueda de las semillas del Verbo, como en momentos posteriores a las semillas del reino, como también, a la revelación trinitaria y pascual. Así la metodología lleva al estudio común, tanto de las fuentes de la revelación cristiana, como de los mitos, símbolos y ritos de los pueblos originarios de América Latina. Se privilegia entonces aquél elemento antropológico que nos habla de la unidad de origen y de un destino común.

\section{PUBLICACIONES SOBRE DIÁLOGO INTERRELIGIOSO Y NUEVOS MOVI- MIENTOS RELIGIOSOS DEL CELAM}

Con el fin de aportar a nuevas y más completas investigaciones al tema del diálogo interreligioso impulsados por el CELAM, nos ha parecido oportuno ofrecer un elenco bibliográfico con las publicaciones que éste ha realizado al respecto.

\subsection{Diálogo interreligioso}

Con respecto al díalogo interreligioso se pueden citar las siguientes producciones editoriales que privilegian la temática de la relación entre judíos y católicos, pero también emerge el tópico del ateísmo, las sectas y nuevos movimientos.

-CELAM, Sección para No Creyentes. (1975). Dios, Problemática de la No Creencia en América Latina. [Celam, Sección para no creyentes, encuentro de profesores de Teología y Filosofía sobre el Tratado de Dios, Jul 25-30, 1974. Lima - Perú] Bogotá: CELAM. (Documentos Celam, Nº 017).

-Mejía, Jorge (1980). Puebla: Diálogo Ecuménico e Interreligioso. Bogotá: CELAM. (Colección Puebla, $\left.\mathrm{N}^{\circ} 24\right)$.

-Vélez Correa, Jaime, SJ. (1989). Sección de Pastoral de la Cultura. La Cultura como Mediación para Evangelizar la No-Creencia en América Latina. Bogotá: CELAM. (Serie Fe y Cultura, No.04). 
-Macias Alatorre, Ramon; Hoeckman, Remi; Osorio Goncalves, Teresa; Gallagher, Michael-Paul. Celam, Dpto de Misiones (1996). Sectas y Nuevos Movimientos Religiosos. Antología de Textos de la Iglesia Católica 1986-1994. Bogotá: CELAM. (Colección Iglesia en Misión, Nº2).

-Urrea Viera, Juan Carlos (1999). El Diálogo Interreligioso: Realidad y Desafíos. Bogotá: CELAM. (Colección Tercer Milenio, N 14.99).

-Fernández Mora, Hugo; Flores Ramos, Mario Angel; Miranda, Mario de Franca; Urrea Viera, Juan Carlos (2001). Comentario Teológico a la Declaración Dominus Iesus. Teólogos Latinoamericanos. Bogotá: CELAM (Colección Documentos de Estudio, $\mathrm{N}^{\circ}$ 03).

-Pliego Carrasco, Fernando (2009). Cambio de época y diálogo intercultural. Una mirada a la realidad social. Bogotá: CELAM. (Colección a la Luz de Aparecida, $\left.\mathrm{N}^{\circ} 24\right)$.

-Cipriani, Gabriel (2009). El ecumenismo y el diálogo interreligioso. Bogotá: CELAM. (Colección a la Luz de Aparecida, N²5).

-Artículos Revista Medellín: COMISIÓN MIXTA (1978). La presencia de Cristo en la iglesia y el mundo. Diálogo entre la alianza reformada mundial y el secretariado para la unidad de los cristianos. (v.4, n.14), pp. 271-299.

-Methol Ferre, Alberto (1981). Nuevo y extraño ecumenismo (v.7, n.27), pp.396408.

-Comisión Teológica del Consejo Ecuménico de la Iglesia (1988). Judíos y católicos. Bautismo, eucaristía y ministerio [BEM] (v.14, n.54), pp. 253-288.

-Carrillo Alday, Salvador; MSPS (1988). Judios y católicos. "Y serán bendecidas en ti todas las familias de la tierra”. Gn. 12, 1-3 en el diálogo judio-cristiano (v.14, n.54), pp. 231-242.

-Comisión para las relaciones religiosas con los judíos (1988). Judíos y católicos. Notas para una correcta presentación de los judios en la predicación y en la catequesis de la Iglesia Católica (v.14, n.54), pp. 185-195.

-Fisher, Eugene (1988). Judíos y católicos. El cristianismo en los primeros tiempos (v.14, n.54), pp. 217-230.

-Klenicki, León (1988). Judios y católicos. El judaísmo rabínico (v.14, n.54), pp. 198-216.

\subsection{Nuevos movimientos religiosos}

Específicamente en cuanto se refiere al diálogo con los nuevos movimientos religiosos, se puedes considerar las siguientes obras publicadas en el formato de libro y en la revista Medellín.

-Equipo de Reflexión Teológico Pastoral (1981). Sectas en América Latina. Bogotá: CELAM. (Documentos CELAM, N 050).

-Sampedro Nieto, Francisco; Escobar, Juan (1991). Sectas y otras doctrinas en la actualidad. Bogotá: CELAM. (Colección Autores CELAM, Nº2).

-Macias Alatorre, Ramón; Hoeckman, Remi; Osorio Goncalves, Teresa; Gallagher, Michael-Paul. CELAM, Dpto de Misiones. DEMIS (1994). Sectas y 
Nuevos Movimientos Religiosos. Antología de Textos de la Iglesia Católica 1986-1994. Bogotá: CELAM. (Colección Iglesia en Misión, No.02)

-López Trujillo, Alfonso, Card.; Calderón, Cipriano; Aguer, Héctor; Kloppenburg, Boaventura; Osorio Goncalves, Teresa; Sampedro Nieto, Francisco; Fuss, Michael; Ferrari, Giuseppe; Baamonde, José María (1997). La Acción Evangelizadora de la Familia ante el Desafio de las Sectas. Bogotá: CELAM (Colección Autores CELAM, N 13).

-Urrea Viera, Juan Carlos (1996). New Age. La Nueva Era. Visión HistóricoDoctrinal y Principales Desafíos. Bogotá: CELAM (Colección Autores Celam, $\left.\mathrm{N}^{\circ} 11\right)$.

-Urrea Viera, Juan Carlos (1998). El Fenómeno de las Sectas. Análisis a Partir del Magisterio Latinoamericano. Antecedentes, Desarrollo y Perspectivas. Bogotá: CELAM (Colección Autores CELAM, N 18).

-Ferrari, Giuseppe; Fuss, Michael; Baamonde, José María; Dermine, Francois; Escobar, Juan Daniel. Secretaría General. Observatorio del CELAM. Consejo Episcopal Latinoamericano (2006). Sectas y nuevos movimientos religiosos. Elementos para ampliar nuestra interpretación y pastoral. Bogotá: CELAM (Colección V Conferencia. Secc. Realidad Social, N 3).

En Revista Medellín: Santagada, Oswaldo (1981). Caracterización y situación de las sectas en América Latina (v.7, n.28), pp. 439-456; Valderrey, José (1986). Las sectas en Centroamérica (v.12, n.45), pp. 103-140.

-Salvatierra, Ángel (1992). Las sectas, desafío a la nueva evangelización (v.18, n.70A), pp. 392-409; Escobar, Juan Daniel (1996). Sectas, cristianismo y catolicismo. Análisis eclesiológico (v.22, n.87), pp. 23-47.

-Galindo, Florencio, CM (1996). Iglesias y grupos evangélicos. Análisis teológico (v.22, n.87), pp. 49-64.

-Hortal, Jesús, SJ. (1996). El fenómeno sectario en el contexto socio-político latinoamericano especialmente en el Brasil (v.22, n.87), pp. 65-86.

-Maccarone, Juan Carlos, Mons. (1996). Sectas fundamentalistas y nuevos movimientos religiosos. Un problema cultural (v.22, n.87), pp. 87-117.

-Sampedro Nieto, Francisco, CM (1996). Religiones, sectas y evangelización desde santo domingo (v.22, n.87), pp. 119-155.

-Pava Piedrahita, Jorge E. (1997). La nueva era. Reflexiones de un psiquiatra. (v.23, n.92), pp. 657-662;

-Saltos Briones, José Vicente (1997). New age elementos básicos para su comprensión (v.23, n.92), pp. 541-597.

-Urrea Viera, Juan Carlos (1997). Aproximación al fenómeno de la nueva era (v.23, n.92), pp. 515-539.

-Vélez Correa, Jaime, SJ. (1997). Nueva era y sectas esotéricas (v.23, n.92), pp. 635-656.

\section{CONCLUSIONES ABIERTAS}

La asunción del diálogo interreligioso por parte del CELAM requirió de un proceso de maduración aún abierto. Desde una preocupación por la 
defensa de la fe, que se basaba en la visión de un continente homogéneamente cristiano y católico, se fue abriendo paso un reconocimiento lento de la diversidad religiosa. Posibilitado, entre otras razones, por la acogida de la categoría de cultura a la reflexión teológica pastoral. En este proceso fue importante también la sección dedicada al diálogo con los no creyentes, que se ocupó de la cuestión religiosa. Esto posibilitó ir dando unos pasos que desde la realización de diagnósticos socio-religiosos de la cuestión religiosa, se pasara a la reflexión más teológica. También en este proceso, se puso más atención a la cuestión de la religiosidad popular.

Este camino de reflexión teológica y pastoral fue ligando religión y cultura, fe y mediaciones culturales, lo que permitió, igualmente, la visibilización del otro religioso. Dentro de los que se encuentran, no sólo las religiones mundiales presentes en el continente, donde destacan los judíos, sino sobre todo, la de los pueblos originarios de nuestro continente y de los pueblos afrodescendientes.

La progresiva reflexión en esta línea facilitó la generación de unas líneas teológicas-pastorales que, a nuestro modo de ver, pueden significar un aporte latinoamericano al desarrollo al diálogo interreligioso. Otorgando a dos de los fundamentos teológicos generales del diálogo interreligioso, a saber: La salvación en la historia y la teología de la creación, una configuración con rostro o acentuaciones latinoamericanas.

Finalmente, para el CELAM la búsqueda del diálogo, tanto ecuménico, como interreligioso se enmarcan también en la búsqueda y promoción del bien común, la paz y la justicia, es decir, en los valores del Reino que siempre son un don de Dios y una tarea para los cristianos. El diálogo interreligioso de características latinoamericanas tiene que abrirse caminos nuevos y creativos, ha necesitado y necesitará de tiempo, discernimiento, personas y comunidades proféticas que den testimonio y abran nuevos caminos. Contamos para ello con una rica tradición que el CELAM va animando, nutrido por una espiritualidad del discipulado misionero, por una teología y eclesiología del Pueblo de Dios y de la comunión al servicio a la humanidad, que nos permite salir al encuentro del "otro religioso" como ante un prójimo.

\section{REFERENCIAS}

-Aparecida (2007). V Conferencia del Episcopado Latinoamericano. En CELAM (Ed. 2014), Las Cinco Conferencias Generales del Episcopado Latinoamericano. Bogotá: Editorial del CELAM - Editorial San Pablo.

-Archivo CELAM (1980). Sección Ecumenismo: Secretariado para la relación con los Judíos. Bogotá: CELAM.

-Archivo CELAM (1987). Sección Ecumenismo. Bogotá: CELAM. 
-CELAM (1974). Dios. Problemática de la no - creencia en América Latina. Bogotá: Editorial del CELAM.

-CELAM (1991). Plan Global 1991-1995. Bogotá: Editorial del CELAM. -CELAM (1995). Plan Global 1995-1999. Bogotá: Editorial del CELAM. -CELAM (1999). Plan Global 1999-2003. Bogotá: Editorial del CELAM. -CELAM (2003). Plan Global 2003-2007. Bogotá: Editorial del CELAM. -CELAM (2007). Plan Global 2007-2011. Bogotá: Editorial del CELAM. -CELAM (2011). Plan Global 2011-2015. Bogotá: Editorial del CELAM. -CELAM (2015). Plan Global 2015-2019. Bogotá: Editorial del CELAM. -CELAM (Ed.) (1997). Fe y Teología en América Latina. Bogotá: Celam.

-CELAM (Ed.) (2003). Dosier Simposio de Diálogo entre Obispos y Expertos en Teología India. Bogotá: Boletín CELAM 229.

-CELAM (2006). Primer Simposio de Teología India. Emergencia indígena: desafío para la pastoral de la Iglesia (vol. 1). Bogotá: CELAM.

-CELAM (2007). Segundo Simposio de Teología India. Diálogo entre Obispos y expertos (vol. 2). Bogotá: CELAM.

-CELAM (2009). Teología India. Tercer Simposio Latinoamericano de Teología India (vol. 3). Bogotá: CELAM.

-CELAM (2013). Teología India. Cuarto Simposio de Teología India (vol. 4). Bogotá: CELAM.

-CELAM. (2015). Teología India. Quinto Simposio de Teología India. Revelación de Dios y Pueblos Originarios (vol. 4). Bogotá: CELAM.

-Concilio Vaticano II (2000). Concilio Ecuménico Vaticano II. Constituciones, Decretos y Declaraciones. Madrid: BAC.

-Congregación para la Doctrina de la fe (2000). Dominus Iesus. Madrid: Palabra.

-Francisco (2013). Exhortación apostólica Evangelii Gaudium. Recuperado de http://www.vatican.va/evangelii-gaudium/po/index.html

-Medellín (1968). II Conferencia del Episcopado Latinoamericano En CELAM (Ed. 2014), Las Cinco Conferencias Generales del Episcopado Latinoamericano. Bogotá: Editorial del CELAM- Editorial San Pablo.

-Merino, P. (2009). Renovación misionera y diálogo ecuménico en Latinoamérica: Convergencias Teológicas. Anales de Teología, 11(2), 313-332.

-Merino, P. (2010). Diversidad religiosa y teología desde América Latina: Visión Panorámica. Reflexiones Teológicas, (6), 57-82.

-Merino, P. (2012). Teología Latinoamericana y Pluralismo Religioso. Salamanca: Editorial Universidad Pontificia de Salamanca.

-Nkafu Nkemnkia, M. (2013). Vitalogía: Algunos aspectos en la base de la cultura africana. Bogotá: Editorial del CELAM.

-Pablo VI (1975). Exhortación Apostólica Evangelii Nuntiandi. Recuperado de http://w2.vatican.va/content/paul-vi/es/apost_exhortations/documents/hf_p-vi_exh_19751208_evangelii-nuntiandi.html

-Pontifical council for inter-religious dialogue (1991). Dialogue and proclamation. Recuperado de http://www.vatican.va/roman_curia/pontifical_councils/interelg/documents/rc_pc_interelg_doc_19051991_dialogue-and-proclamatio_en.html 
-Puebla (1979). III Conferencia del Episcopado Latinoamericano En CELAM (Ed. 2014), Las Cinco Conferencias Generales del Episcopado Latinoamericano. Bogotá: Editorial del CELAM- Editorial San Pablo.

-Rio de Janeiro (1955). I Conferencia del Episcopado Latinoamericano. En CELAM (Ed. 2014), Las Cinco Conferencias Generales del Episcopado Latinoamericano. Bogotá: Editorial del CELAM- Editorial San Pablo.

-Santo Domingo (1992). IV Conferencia del Episcopado Latinoamericano En CELAM (Ed. 2014), Las Cinco Conferencias Generales del Episcopado Latinoamericano. Bogotá: Editorial del CELAM- Editorial San Pablo.

-Scannone, J. C. (2017). La Teología del Pueblo: Raíces Teológicas del Papa Francisco. Santander: Sal Terrae.

Sumario: Introducción; 1. De la defensa de la fe al encuentro-diálogo con la diversidad cultural y religiosa. Sinopsis histórica; 2. El diálogo interreligioso en las Conferencias Generales del Episcopado Latinoamericano; 3. El diálogo con el Pueblo Judío en América Latina; 4. La Teología India y Afroamericana: los elementos teológicos que animan el diálogo interreligioso; 4.1. El énfasis histórico de la salvación; 4.2. Las perspectivas de la teología de la creación; 5. Publicaciones sobre diálogo interreligioso y nuevos movimientos religiosos del CELAM; 5.1. Diálogo interreligioso; 5.2. Nuevos movimientos religiosos; Conclusiones abiertas; Referencias. 